\title{
A Model Study of Residence Time of Metal Droplets in the Slag in BOF Steelmaking
}

\author{
Qing Lin HE and Nicholas STANDISH
}

Department of Materials Engineering, The University of Wollongong, Wollongong, N.S.W. 2500, Australia.

(Received on October 26, 1989; accepted in the final form on January 26, 1990)

\begin{abstract}
Residence time of metal droplets generated by an oxygen jet impinging on molten bath surface in the slag was investigated in a 3-D two phase (mercury/glycerine) model. The residence time $\left(\tau=Q_{2} / q_{1}\right)$ was obtained from measurements of the amount of emulsified mercury in glycierine at steady state $\left(Q_{2}\right)$ and the drop generation rate $\left(q_{1}\right)$. It has been found that the mean residence time increases with increasing top gas flow rate and decreases with increasing bottom gas flow rate. Also, it increases at first and then decreases with increasing lance height. Maximum mean residence time was achieved at a certain lance height.
\end{abstract}

KEY WORDS: residence time; droplets; steelmaking.

\section{Introduction}

In the course of oxygen blowing in a BOF vessel, metal droplets of various sizes are ejected from the metal bath into the slag. ${ }^{1-3)}$ These droplets fall back into the bath after having resided a certain time in the slag. The residence time or settling time of the metal droplets greatly affects the refining rate of the BOF steelmaking process. ${ }^{4,5}$

It is agreed that the metal/slag emulsion which contains a great number of metal droplets creates a large surface area for reactions (up to about $20 \mathrm{~cm}^{2} / \mathrm{g}$ of emulsified metal ${ }^{3,4)}$ ), and it is of a great importance for the understanding of refining reactions of the BOF steelmaking process. According to the emulsion model of dephosphorization, ${ }^{5}$ the refining rates due to the reactions occurring in the metal/slag emulsion depend on the amount of metal emulsified in the slag, the size distribution of droplets ejected and their residence time in the slag. The amount of metal emulsified in the slag and the size distribution of the metal droplets provide the total surface area for the reactions, whilst the residence time of the droplets in the slag allows them the opportunity to react with the slag. The former two have been studied by many investigators $^{1-3,5-9)}$ either in an industrial scale converter or in model experiments. However, due to the difficulty in obtaining the residence time experimentally, either from an industrial scale converter or from a model, very few experimental studies ${ }^{4}$ on the latter have been carried out.

As far as is known, the only measurement of the residence time in a $\mathrm{BOF}$ vessel was performed by Price, ${ }^{4)}$ who employed a radioactive gold isotope tracer technique. The average residence time obtained from this investigation was $2.0 \pm 0.5 \mathrm{~min}$. However, the assumptions made in this study may have resulted in the estimated value of the mean residence time being larger than it should have been. This will be discussed later.

The purpose of the present investigation is to study the residence time of the curoplets dispersed in the slag, with emphasis on the effect of blowing parameters on the residence time, in the $\mathrm{BOF}$ steelmaking process, by use of a two-phase (mercury/glycerine) model. The results of this study should provide a better understanding of the BOF process, in terms of the refining rate.

\section{Definition of Mean Residence Time}

During the blow, metal droplets are ejected out of the bath into slag due to impingement of gas jet on the bath surface. The droplets fall back into the bath after spending a certain residence time in slag. The results of preliminary experiments in which mercury and glycerine were used to simulate liquid steel and slag, respectively, show that the amount of mercury in glycerine accumulates in the initial stage of the blow and then reaches steady state after a certain length of blowing time (see Fig. 1). This indicates that the rate of generation of the droplets is initially higher than the rate at which the droplets return to the bath from the slag layer, and these two rates tend to become equal as the blowing time increases.

Droplets of different size have different residence time in the slag, due to different settling velocities. It is assumed that the droplets have residence time distribution as shown in Fig. 2.

After a blowing period of $0-t$, the droplets which are generated at time $t_{1}$ between $0-t$, and whose residence time is less than $t-t_{1}$ have returned to the bath. If the drop generation rate is assumed to be constant throughout the blow, the total amount of droplets produced and the total amount of droplets returned within this period can be expressed by the 


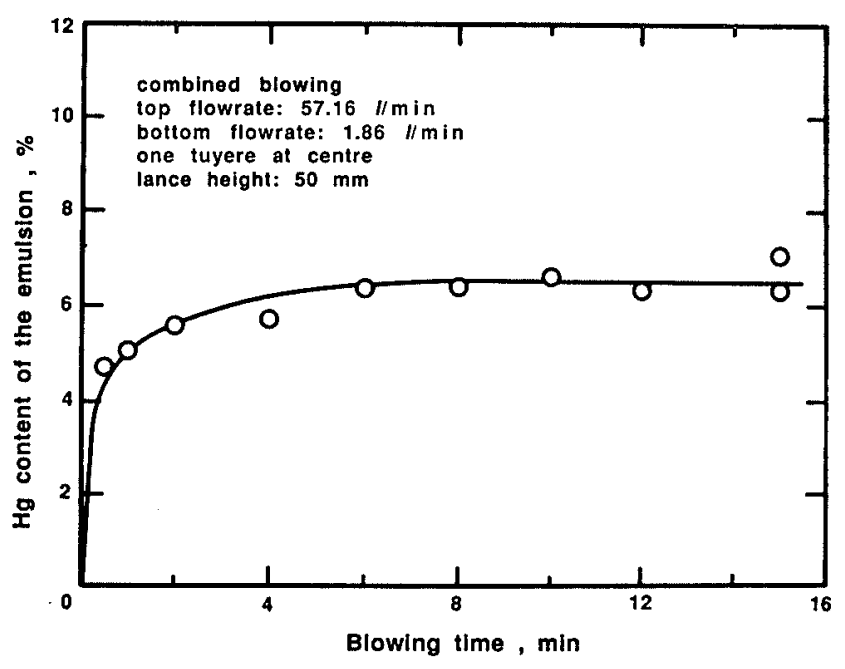

Fig. 1. Build-up of mercury content in glycerine at the initial stage of blowing.

following equations.

$$
\begin{aligned}
& Q_{1}=q_{1} \cdot t \\
& Q_{3}=\int_{0}^{t} q_{1} \int_{0}^{t-t_{1}} \phi(\tau) d \tau d t_{1}=q_{1} \int_{0}^{t} \int_{0}^{t-t_{1}} \phi(\tau) d \tau d t_{1}
\end{aligned}
$$

where, $q_{1}$ : drop generation rate, constant throughout blow

$Q_{1}$ : the total amount of droplets produced

$Q_{3}$ : the total amount of droplets returned to the bath

$t$ : blowing time

$\phi(\tau)$ : residence time distribution density

$\tau$ : residence time.

From material balance the amount of droplets in slag layer $\left(Q_{2}\right)$ is

$$
\begin{aligned}
Q_{2} & =Q_{1}-Q_{3} \\
& =q_{1} \cdot t-q_{1} \int_{0}^{t} \int_{0}^{t-t_{1}} \phi(\tau) d \tau d t_{1}
\end{aligned}
$$

If it is assumed that all droplets have the same residence time, $\tau_{R}$, in the slag, then the corresponding residence time distribution is shown in Fig. 3. Mathematically,

$$
\phi_{R}(\tau)= \begin{cases}\infty & \tau=\tau_{R} \\ 0 & \tau \neq \tau_{R}\end{cases}
$$

No droplets return to the bath during the period of blowing time $0-\tau_{R}$, that is,

$$
Q_{3}=q_{1} \int_{0}^{\tau_{R}} \int_{0}^{\tau_{R}-t_{1}} \phi_{R}(\tau) d \tau d t=0
$$

and, steady state is reached at time $\tau_{R}$. So, we have,

$$
\begin{aligned}
Q_{2} & =q_{1} \cdot t_{s}-q_{1} \int_{0}^{t_{s}} \int_{0}^{t_{s}-t_{1}} \phi(\tau) d \tau d t_{1} \\
& =q_{1} \cdot \tau_{R}-q_{1} \int_{0}^{\tau_{R}} \int_{0}^{\tau_{R}-t_{1}} \phi_{R}(\tau) d \tau d t_{1} \\
& =q_{1} \cdot \tau_{R} \ldots \ldots \ldots \ldots \ldots \ldots \ldots \ldots \ldots \ldots \ldots \ldots \ldots \ldots \ldots \ldots \ldots \ldots \ldots
\end{aligned}
$$

where, $t_{s}$ : time needed for attaining steady state.

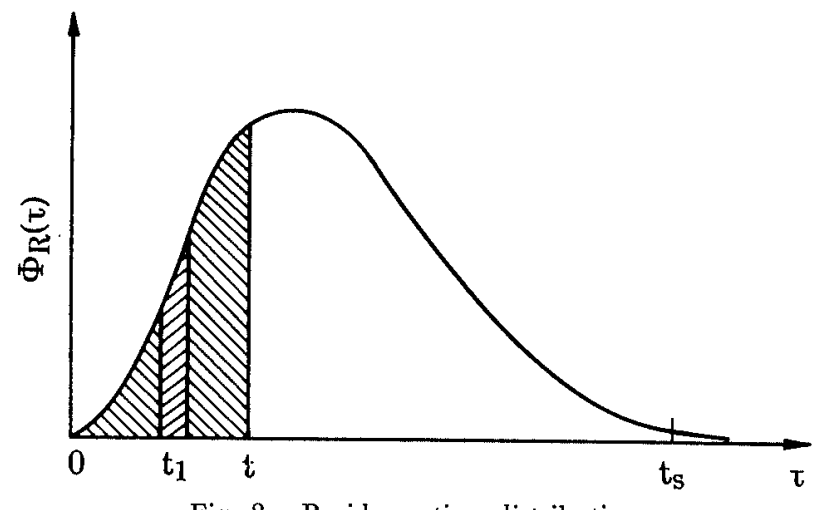

Fig. 2. Residence time distribution.

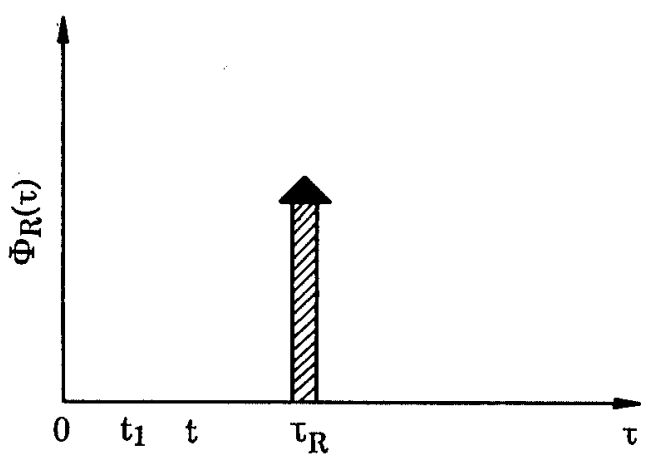

Fig. 3. Residence time distribution of the plug flow.

From Eq. (6) the mean residence time is then simply

$$
\tau_{R}=Q_{2} / q_{1}
$$

\section{Experimental}

The apparatus used in the present work is schematically shown in Fig. 4. Mercury and glycerine were used to simulate molten steel and slag, respectively. Experiments were carried out in a three-dimensional (3D) BOF model made of Plexiglas, with internal dimensions of $\phi 195 \mathrm{~mm} \times 270 \mathrm{~mm}$ and divided into two parts by a slide gate at the interface between mercury and glycerine. Depth of the mercury bath was $75 \mathrm{~mm}$ and the thickness of the glycerine layer was $25 \mathrm{~mm}$. Nitrogen gas was blown into the system at predetermined flow rates from top lance with a nozzle of $2 \mathrm{~mm}$ ID and from bottom tuyeres with an outlet of $1.5 \mathrm{~mm} \mathrm{ID}$, as well. At the required time the gas supply was cut off and the slide gate simultaneously closed to separate the mercury/glycerine emulsion from the mercury metal in the lower portion of the model. Shutting off the gas supply was controlled by a solenoid valve, which ensured that the gas supply was turned off at the same time for each run.

In the present work, two parameters needed to be determined from the experiments, the total amount of mercury in the emulsion at steady state, and the drop generation rate, i.e. $Q_{2}$ and $q_{1}$ in Eq. (7). The former was obtained after the blow of 8 min. The blowing time for obtaining the steady state was selected on the basis of the preliminary results shown in Fig. 1. Average droplet generation rate_within the period of 


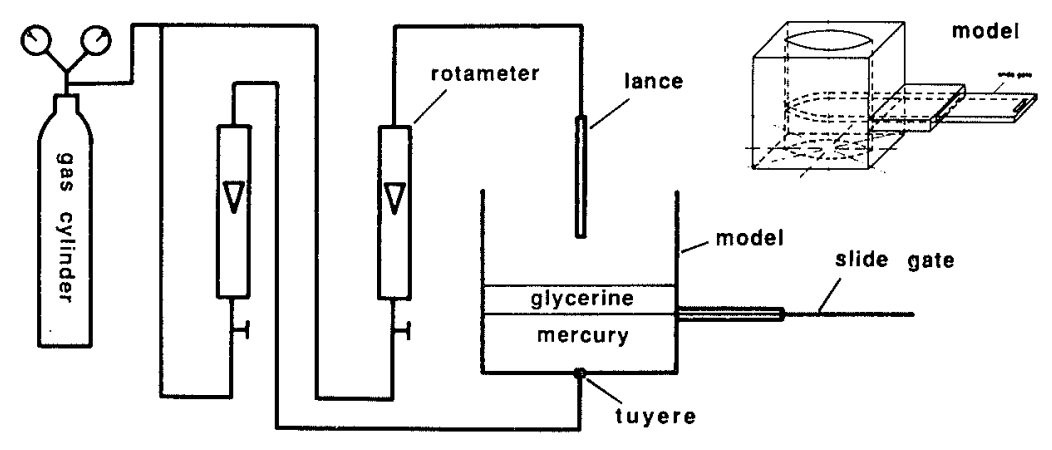

Fig. 4.

Line diagram of experimental apparatus.

blowing time of $1.0 \mathrm{~s}$ was taken as the latter, and assumed to be constant throughout the period of the blow for a given blowing condition. Appendix shows calculation of $q_{1}$ and data of $Q_{2}$ and $q_{1}$, obtained from the present experiments under different blowing conditions.

The mercury content of the emulsion was determined by standard density bottle technique. Because of absorption of water vapour from the atmosphere the viscosity of glycerine decreases with time. To overcome any possible influence of the mercury concentration of the emulsion, the glycerine was renewed after every 20 runs.

\section{Results}

Figs. 5 to 7 show the effect of top gas flow rate, bottom gas flow rate of combined blowing and top lance height on the mean residence time, respectively. From these results it is evident that:

(1) the mean residence time significantly increases with increasing top gas flow rate (Fig. 5),

(2) the mean residence time decreases with increasing bottom gas flow rate in combined blowing process (Fig. 6), and

(3) the mean residence time increases at first, and then decreases as the top lance height increases. A maximum residence time is obtained at a certain lance height (Fig. 7).

The residence time of droplets in slag mainly depends on the following factors.

(1) Physical properties of slag, e.g., viscosity and density. The higher the viscosity and density are, the longer is the residence time.

(2) Turbulence of slag layer, which results in longer residence time.

(3) Degree of slag foaming which leads to an increase in thickness of slag layer and a decrease in bulk density of slag. The decrease in the slag bulk density results in higher settling velocity of the droplets. The increase in the thickness increases the distance for the droplets to travel in the slag.

(4) Drop size distribution. The smaller the droplets, the longer is the residence time.

(5) Height to which the droplets are ejected. Obviously, the larger the height, the longer is the time period during which the droplets are out of the bath.

(6) Decarburization rate. The dispersed droplets are decarburized during their stay in the slag to form $\mathrm{CO}$ bubbles, which may attach themselves to the

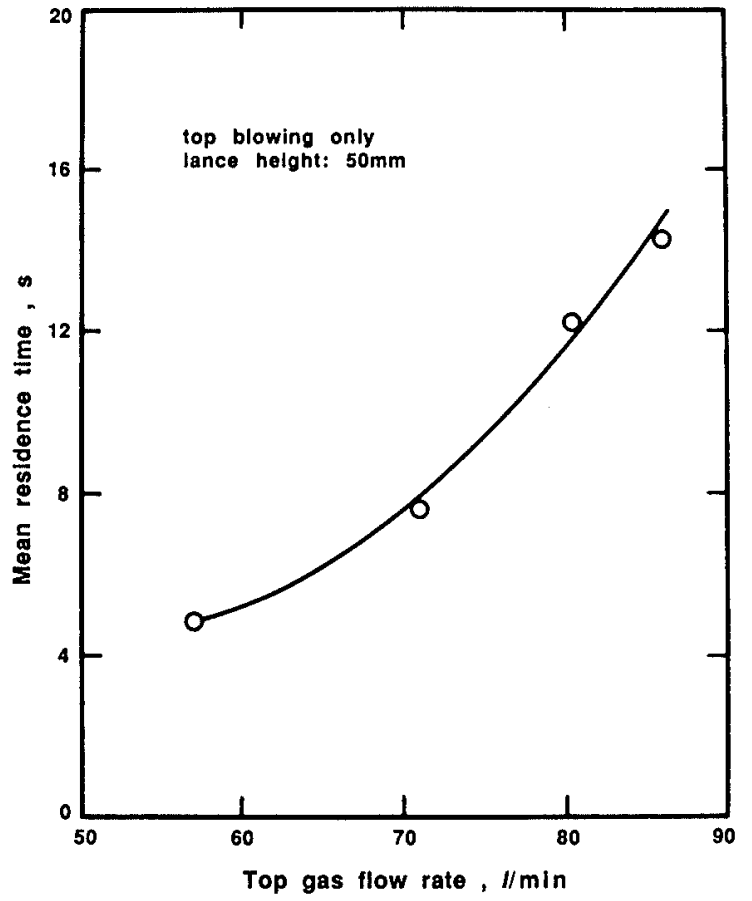

Fig. 5. Effect of top gas flow rate on the mean residence time.

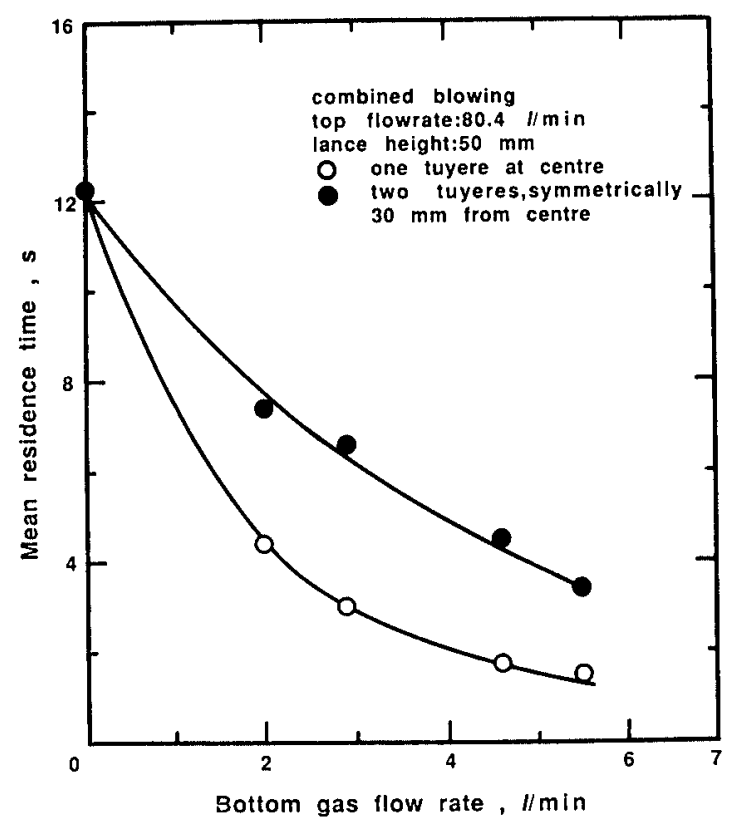

Fig. 6. Effect of bottom gas flow rate on the mean residence time. 


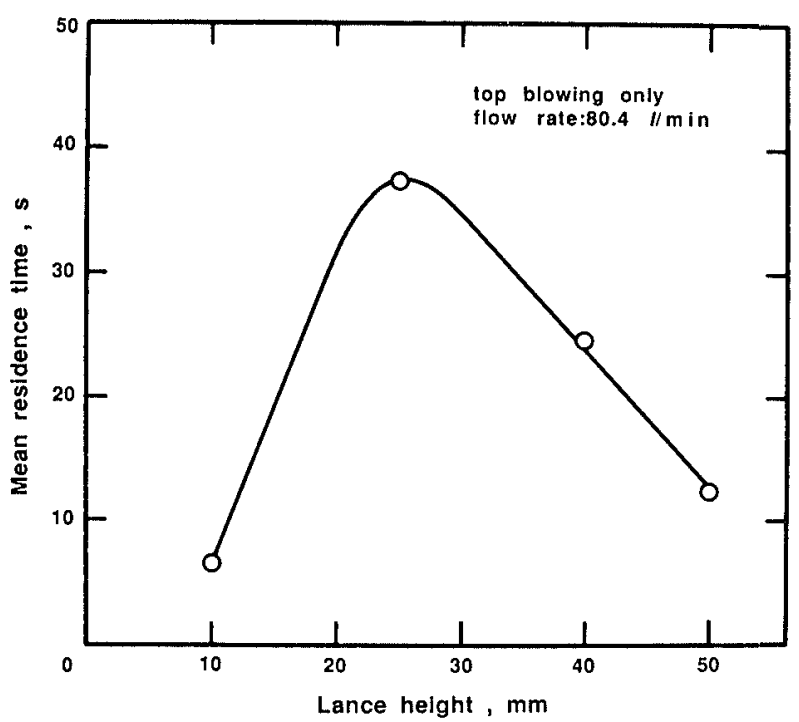

Fig. 7. Effect of lance height on the mean residence time.

droplets. The GO bubbles significantly affect the residence time of the droplets in the slag. ${ }^{10,11)}$ The existence of the bubbles results in a decrease in the settling velocity of the droplets, or even a change in direction of movement of small droplets. ${ }^{10,11)}$ Therefore, the occurrence of decarburization of the droplets in the slag leads to an increase in their residence time in the slag. Unfortunately, this phenomenon could not be simulated in the present cold model experiments.

The results shown in Figs. 5 to 7 can be explained from the viewpoint of the factors described above. Fig. 5 shows the effect of top gas flow rate on the mean residence time. Increase in top gas flow rate increases (i) degree of slag foaming, (ii) turbulence of slag phase, (iii) height to which the droplets are ejected and, (iv) size of the droplets. ${ }^{6)}$ As discussed above, these parameters, except the drop size and degree of slag foaming, all result in longer residence time of the droplets in the slag. The increase in the average residence time with top gas flow rate, as shown in Fig. 5 , is probably due to (ii) and (iii) above. The effects of drop size and degree of slag foaming are relatively small compared with the combined influence of the other two factors.

The result in Fig. 6 shows that the residence time decreases with increase in bottom gas flow rate of combined blowing. Among the factors influencing the residence time discussed earlier, the drop size is the only factor significantly influenced by bottom blowing. The increase in droplet size accompanying bottom blowing ${ }^{6)}$ results in a decrease in the mean residence time.

As shown in Fig. 7, the average residence time at first increases and then decreases as the lance height is increased. A maximum value is obtained at a critical lance height. This result is very similar to that of an increase in the top gas flow rate, because they both lead to an increase in the jet momentum at the bath surface. As discussed in connection with the effect of top gas flow rate, decrease in the lance height results in an increase in the mean residence time in this region. Further decrease in the lance height causes the formation of a deep depression in the bath surface. Under these conditions big bubbles form around the nozzle ${ }^{6)}$ and, on escaping from the bath, they carry many large fragments of the lower phase into the upper phase with them. Being large in size, these fragments fall back into the bath very soon after generation, and this explains the observed decrease in the residence time as shown in Fig. 7.

\section{Discussion}

Although the conditions in the model and in the real system can not be identical, and therefore the absolute values of the residence times may be different, the influence of the factors relating to blowing conditions on the residence time is considered to be not too different in the two cases. Therefore, it is reasonable to expect similarity of the variation of the residence time with the blowing parameters between the model and the converter. Hence, the results of the present work may be used, at least qualitatively, to explain the phenomena occurring in the real system, and gain better understanding of the process.

In the previous paper, ${ }^{6)}$ the effect of bottom blowing on the refining rate of the BOF steelmaking was discussed. It was pointed out that the increased proportion of large droplets due to the bottom blowing would decrease the effect of the bottom blowing on the steelmaking refining rates that may be expected on the basis of the droplet generation rate (ejected weight per unit time) or the total amount of metal emulsified in the slag layer alone. ${ }^{6)}$ This is because larger droplets create smaller surface area per unit mass. In making this conclusion, however, the residence time was not taken into account. Whether and how the residence time influences the effect of the bottom blowing on the steelmaking refining rates depends on the relative value of the residence time and the reaction time needed for obtaining the chemical equilibrium between the droplets and the slag. The refining rate will be increased by the bottom blowing if the residence time is equal or greater than the required reaction time.

Although the introduction of bottom blowing results in a decrease of droplet residence time (Fig. 6), the refining rate may, or may not, be decreased, as this depends on the reaction time, metal emulsification rate and droplet size distribution. Oeters ${ }^{14)}$ has shown that for reasonable values of the mean droplet size and average residence time, the droplets will essentially reach equilibrium with the slag, even with the relatively low mass transfer coefficient expected ${ }^{16)}$ for fine droplets suspended in a slag. This suggests that the residence time is longer than the reaction time required for equilibrium, and the decrease in the residence time due to the introduction of bottom blowing may actually increase the refining rate of the BOF steelmaking.

As is known, the residence time of the droplets in the slag is of importance to the refining rate due to the reaction occurring in the emulsion But its absolute 
value is, at present, still uncertain. The average residence times of a wide range viz., $0.25 \mathrm{~s}-2.5 \mathrm{~min}$, have been evaluated by experiment, ${ }^{4)}$ or obtained from experience. ${ }^{12-15)}$

Price $^{4)}$ measured the mean residence time in an industrial scale converter using a radioactive gold isotope tracer technique. In this work, the period from the instant at which the isotope was added into the bath to the time at which the two radioactivity levels, viz. those of bath and droplets, became similar was taken as a half of the average residence time. A value of $2.0 \pm 0.5 \mathrm{~min}$ was obtained. However, this value may be larger than it should have been, because:

(i) The isotope needed a certain time to dissolve in the bath so that some of the ejected droplets were radioactive and some of them were not. This gave an impression of lower droplet replacement rate than it was in reality and consequently longer residence times were obtained than they should have been.

(ii) The time taken for the two activity levels (bath and droplets) to become similar was taken as one half of total residence time. This value also represented the time taken for non-radioactive droplets to return to the bath. Because smaller droplets stay in the slag longer under otherwise identical conditions, the residence time estimated in this way was actually that of the smallest droplets among those which had returned to the bath. Consequently, the residence time obtained from this work was greater than the average value.

(iii) The assumption that the time for radioactive droplets to be ejected from the bath to the emulsion was equal to that for non-radioactive droplets to return to the bath from the emulsion also resulted in residence time overestimates because the former is much smaller than the latter.

In the work of Urquhart et al. ${ }^{12)}$ a mean residence time of $0.25 \mathrm{~s}$ was assumed, based upon the observation of room temperature experiments, for their mass transfer calculation of hot model experiments.

Kozakevitch, ${ }^{13)}$ following his investigation into the metal/slag emulsion, pointed out that the mean residence time may be of the order of 1-2 min, perhaps much less, but certainly not more.

In the work by Oeters, ${ }^{14)}$ on kinetic treatment of chemical reactions in emulsion metallurgy, an average residence time of $1.0 \mathrm{~min}$ was suggested. This suggested value was used by Jahanshahi and Belton ${ }^{15)}$ in their dephosphorization calculation in which the reactions occurring in the emulsion were considered to dominate the overall refining rate of the BOF steelmaking process. It was found that the observed rate was broadly in accord with expected rate for the emulsion mechanism.

From the above discussion it appears that a value of $1.0 \mathrm{~min}$, or so, for the mean residence time of metal droplets is reasonable.

\section{Conclusions}

The residence time of metal droplets produced by an oxygen jet impinging on the bath surface in the slag has been studied in a 3-D two phase (mercury/ glycerine) model at room temperature. Although the existence of $\mathrm{GO}$ bubbles due to decarburization of the droplets could not be simulated in this model study, and there exist differences in properties of upper and lower phases between the model and the real system, the results from the present investigation can be used, at least qualitatively, to explain the phenomena occurring in the real system, and to further our understanding of the process.

Actual experimental results of this study have shown that:

(1) The mean residence time increases with increase in the top gas flow rate and decreases with increasing the bottom gas flow rate of combined blowing.

(2) The mean residence time at first increases and then decreases as the lance height is increased. A maximum value of the residence time is obtained at a certain lance height.

(3) The introduction of bottom blowing into LD converter causes an increase in the proportion of large droplets and a decrease in the residence time of the droplets in the slag. The former would result in less effect of the bottom blowing on steelmaking refining rate than may be expected on the basis of the mass generation rate of the droplets. ${ }^{6)}$ The latter would increase or decrease the steelmaking refining rate, depending on relative value of the residence time to the reaction time required for obtaining equilibrium with the slag.

\section{Acknowledgements}

We wish to thank Dr. G. R. Belton and his colleagues in BHP Gentral Research Laboratories for their helpful discussion. We are also grateful to $\mathrm{Mr}$. C. Carey in BHP Slab \& Plate Products Division, Port Kembla, for his assistance. Financial support by BHP Steel International is gratefully acknowledged.

\section{REFERENCES}

1) H. W. Meyer, W. F. Porter, G. C. Smith and J. Szekely: J. Met., 20 (1968), 35.

2) B. Trentini: Trans. Metall, Soc. AIME, 242 (1968), 2377.

3) A. Chatterjee, N.-O. Lindfors and J. A. Wester: Ironmaking Steelmaking, 3 (1976), 21.

4) D. J. Price: Process Engineering of Pyrometallurgy, M. J. Jones, ed., Inst. Mining Metall, London, (1974), 8.

5) J. Schoop, W. Resch and G. Mahn: Ironmaking Steelmaking, 5 (1978), 72.

6) N. Standish and Q.L. He: ISIJ Int., 29 (1989), 455

7) Q.L. He and N. Standish: ISIJ Int., 30 (1990), 305.

8) S. C. Koria and K. W. Lange: Metall. Trans. B., 15B (1984), 109.

9) S. G. Koria and K. W. Lange: Ironmaking Steelmaking, 13 (1986), 236.

10) V. G. Baryshnikov, A. A. Deryabin, S. I. Popel' and M. I. Panfilov: Izv. An. SSSR. Metally, (1970), No. 2, 106. (English translation: Russian Metallurgy, 2 (1972), 56).

11) S. P. Mochalov, E. I. Liverts, K. M. Shakirov and S. A. Shipilov: Izv. V.U.Z. Chernaya Metall., 2 (1986), 117.

12) R. C. Urquhart and W. G.-Danport: Can. Metall. Quar., 
12 (1973), 507.

13) P. Kozakevitch: J. Met., 29 (1969), 57.

14) F. Oeters: Steel Res., 56 (1985), 69.

15) S. Jahanshahi and G. R. Belton: Fifth Int. Iron and Steel Congress, Process Technology Proceedings, Vol. 6, ISSAIME, Warrendale, (1986), 641.

16) K. W. Lange: Arch. Eisenhütlenwes., 42 (1971), 233.

\section{Appendix}

(1) Calculation of $q_{1}$ :

Total amount of mercury in glycerine after nitrogen blow of $1.0 \mathrm{~s}$ into the bath was divided by the blowing time $(1.0 \mathrm{~s})$ to give the average drop generation rate, assuming that no droplets fell back into the bath during this time.

For the purpose of reproducibility of experimental procedure, some of the points were repeated. In these cases, the average values of $q_{1}$ and $Q_{2}$ were used for calculation of the residence time.

(2) Variation of $q_{1}$ and $Q_{2}$ with blowing conditions are given in the following tables.

Table A-1. Variation of $q_{1}$ and $Q_{2}$ with top flow rate.

\begin{tabular}{llll}
\hline $\begin{array}{c}\text { Blowing } \\
\text { conditions }\end{array}$ & $\begin{array}{c}\text { Top flow } \\
\text { rate } \\
(l / \mathrm{min})\end{array}$ & \multicolumn{1}{c}{$\begin{array}{c}q_{1} \\
(\mathrm{~g} / \mathrm{s})\end{array}$} & \multicolumn{1}{c}{$\begin{array}{c}Q_{2} \\
(\mathrm{~g})\end{array}$} \\
\hline Top blowing only & 57.16 & $2.13,2.49$ & 11.2 \\
Lance height : & 71.0 & $4.43,3.85,4.74$ & 33.02 \\
$50 \mathrm{~mm}$ & 80.4 & $5.04,6.69,5.7$ & $62.0,80.19$ \\
& 86.0 & $7.14,6.45$ & 97.05 \\
\hline
\end{tabular}

Table A-2. Variation of $q_{1}$ and $Q_{2}$ with lance height.

\begin{tabular}{lrll}
\hline $\begin{array}{c}\text { Blowing } \\
\text { conditions }\end{array}$ & $\begin{array}{c}\text { Lance } \\
\text { height } \\
(\mathrm{mm})\end{array}$ & \multicolumn{1}{c}{$\begin{array}{c}q_{1} \\
(\mathrm{~g} / \mathrm{s})\end{array}$} & \multicolumn{1}{c}{$\begin{array}{c}Q_{2} \\
(\mathrm{~g})\end{array}$} \\
\hline Top blowing only & 0 & 27.27 & $196.21,167.66$ \\
Top flow rate: & 25 & $11.61,15.64$ & 508.54 \\
$80.4 \mathrm{l} / \mathrm{min}$ & 40 & $8.49,7.9$ & 200.95 \\
& 50 & $5.04,6.69,5.7$ & $62.0,80.19$ \\
\hline
\end{tabular}

Table A-3. Variation of $q_{1}$ and $Q_{2}$ with bottom flow rate.

\begin{tabular}{llll}
\hline $\begin{array}{c}\text { Blowing } \\
\text { conditions }\end{array}$ & $\begin{array}{c}\text { Bottom } \\
\text { flow } \\
\text { rate } \\
(l / \mathrm{min})\end{array}$ & \multicolumn{1}{c}{$\begin{array}{c}q_{1} \\
(\mathrm{~g} / \mathrm{s})\end{array}$} & \multicolumn{1}{c}{$\begin{array}{c}Q_{2} \\
(\mathrm{~g})\end{array}$} \\
\hline Combined blowing & 0 & $5.04,6.69,5.7$ & $62.0,80.19$ \\
Top flow rate: & 2.0 & $24.2,14.6$ & 85.56 \\
$\quad 80.4 \mathrm{l} / \mathrm{min}$ & 2.89 & $35.4,30.79$ & $109.91,89.85$ \\
Lance height : & 4.58 & $57.72,60.43$ & 104.8 \\
$\quad 50 \mathrm{~mm}$ & 4.58 & 101.5 \\
\hline
\end{tabular}

Table A-4. Variation of $q_{1}$ and $Q_{2}$ with bottom flow rate.

\begin{tabular}{lcll}
\hline \multicolumn{1}{c}{ Blowing } \\
conditions & $\begin{array}{c}\text { Bottom } \\
\text { flow } \\
\text { rate } \\
(l / \mathrm{min})\end{array}$ & \multicolumn{1}{c}{$\begin{array}{c}q_{1} \\
(\mathrm{~g} / \mathrm{s})\end{array}$} & \multicolumn{1}{c}{$\begin{array}{c}Q_{2} \\
(\mathrm{~g})\end{array}$} \\
\hline Gombined blowing & 0 & $5.04,6.69,5.7$ & $62.0,80.19$ \\
$\begin{array}{c}\text { Top flow rate: } \\
80.4 l / \text { min }\end{array}$ & 2.0 & $26.56,26.99$ & $209.95,186.8$ \\
$\begin{array}{c}\text { Lance height: } \\
\text { 50 mm }\end{array}$ & 2.89 & 32.12 & $213.9,212.5$ \\
$\begin{array}{c}\text { Two tuyeres, } 30 \mathrm{~mm} \\
\text { from centre } \\
\text { symmetrically }\end{array}$ & 4.58 & $57.36,50.61$ & $231.33,258.77$ \\
\hline
\end{tabular}

